\title{
Impact of the COVID-19 pandemic on interest in renal diseases
}

\author{
Ozgur Akin Oto ${ }^{1}$ (D) $\cdot$ Sinan Kardeş ${ }^{2}$ (D) $\cdot$ Nurane Guller $^{1}$ (D) $\cdot$ Seda Safak $^{1}$ (D) $\cdot$ Ahmet Burak Dirim $^{1}$ (D) $\cdot$ \\ Yağmur Başhan $^{3}$ (D) Erol Demir ${ }^{1}$ (D) Ayse Serra Artan ${ }^{1}$ (D) $\cdot$ Halil Yazıcı $^{1}$ (D) $\cdot$ Aydın Turkmen $^{1}$ (D)
}

Received: 25 May 2021 / Accepted: 23 July 2021 / Published online: 2 August 2021

(C) The Author(s), under exclusive licence to Springer-Verlag GmbH Germany, part of Springer Nature 2021

\begin{abstract}
There is an information gap about the public's interest in nephrological diseases in the COVID-19 era. The objective was to identify public interest in kidney diseases during the pandemic. In this infodemiology study, Google Trends was queried for a total of 50 search queries corresponding to a broad spectrum of nephrological diseases and the term "nephrologist." Two time intervals of 2020 (March 15-July 4 and July 5-October 31) were compared to similar time intervals of 2016-2019 for providing information on interest in different phases of the pandemic. Compared to the prior 4 years, analyses showed significant decreases in relative search volume (RSV) in the majority (76\%) of search queries on March 15-July 4, 2020 period. However, RSV of the majority of search queries $(\approx 70 \%)$ on July 5-October 31,2020 period was not significantly different from similar periods of the previous 4 years, with an increase in search terms of amyloidosis, kidney biopsy, hematuria, chronic kidney disease, hypertension, nephrolithiasis, acute kidney injury, and Fabry disease. During the early pandemic, there have been significant decreases in search volumes for many nephrological diseases. However, this trend reversed in the period from July 5 to October 31, 2020, implying the increased need for information on kidney diseases. The results of this study enable us to understand how COVID-19 impacted the interest in kidney diseases and demands/needs for kidney diseases by the general public during the pandemic.
\end{abstract}

Keywords Kidney diseases; · Nephrology; · Nephrological diseases; · Nephrologist; · COVID-19; · Google Trends

\section{Introduction}

The coronavirus disease-2019 (COVID-19) pandemic has caused devastating effects all over the world (El-Sayed et al. 2021; Yin et al. 2021; Alola and Olowu 2020). Globally, a total of 70,829,855 confirmed cases of COVID-19, including 1,605,091 deaths, have been reported to the World Health Organization so far (WHO (World Health Organization) 2021). This pandemic, which deeply affected health systems and caused significant changes in nephrology practice as well.

Responsible Editor: Lotfi Aleya

Ozgur Akin Oto

maviozgurluk@gmail.com

1 Department of Nephrology, Istanbul Faculty of Medicine, Istanbul University, Istanbul, Turkey

2 Department of Medical Ecology and Hydroclimatology, Istanbul Faculty of Medicine, Istanbul University, Istanbul, Turkey

3 Department of Nephrology, Haseki Education Research Hospital, Istanbul, Turkey
Although the first publications at the beginning of the epidemic reported that renal complications of COVID-19 were low (Deng et al. 2020; Guan et al. 2020), later publications revealed that individuals with kidney disease are vulnerable to this disease (Kliger and Silberzweig 2020). Also, it was found that COVID-19-related acute kidney injury (AKI) was several times higher in USA data (Arentz et al. 2020) compared to the previous Chinese series (Yang et al. 2020). Kidney transplant operations were stopped in many centers during the pandemic. The reasons for this were COVID-19 test limitations that prevented the detection of infected donors and recipients, the incomplete understanding of the transmission dynamics of SARS-COV2, and the possibility of de-novo immunosuppression worsening the course of COVID-19 (Loupy et al. 2020; Lentine et al. 2020). Indeed in the studies in our group and Turkish Society of Nephrology, the mortality of COVID-19 in renal transplant patients $12.5 \%$ and $11.1 \%$ respectively (Ozturk et al. 2020; Demir et al. 2020). Also, both nephrologists and patients faced difficult decisions regarding the management of glomerular diseases (Bomback et al. 2020).

Health systems have struggled to cope with the increasing spread of the infection and many clinics/wards have converted to COVID-19 units. Therefore, important disruptions 
occurred in the delivery of routine health services. Mobilization restrictions, problems in accessing healthcare facilities, and the effective role of nephrologists in combating the COVID pandemic restricted the patient's access to the nephrologist. The widespread use of telemedicine applications as a result of digitalization in health systems and disruptions in the health system might lead to an increased interest in internet-based searches in the population.

Google Trends ${ }^{\mathrm{TM}}$ is a widely used tool to monitor Big Data by analyzing Google TM search engine queries (Mavragani and Ochoa 2019). It is possible to analyze the relative search volume (RSV) and obtain information about trends in public interest in a particular subject with Google Trends ${ }^{\mathrm{TM}}$, which is also used to analyze the temporal and geographical trends of search queries (Mavragani and Ochoa 2019; Kardeș and Kardeș 2021; Doepker et al. 2021). In many studies, Google Trends ${ }^{\mathrm{TM}}$ has proven to be worthwhile for investigating epidemics and surveying public interest (Eysenbach 2009; Mavragani and Ochoa 2019; Kardeș 2021). This tool has been used in previous outbreaks including Influenza (Lampos et al. 2015; Lu et al. 2018) and Zika virus (Teng et al. 2017). Besides, population-level interest in several fields such as urology (Bhambhvani et al. 2020), rheumatology (Kardeş et al. 2021a, 2021b), dermatology (Kutlu 2020; EsenSalman et al. 2021), plastic surgery (Dhanda et al. 2020), pediatric neurosurgery (Güdük et al. 2021), and otolaryngology (Pier et al. 2020) during the COVID-19 pandemic has been investigated analyzing Google Trends data. These studies show that it is possible to integrate Google Trends into the medical field as a valuable source of epidemiological data for monitoring the public interest.

During the pandemic, there is an information gap about the public's interest in nephrological diseases and nephrologists. This information enables us to understand how COVID-19 has impacted the interest in nephrology-related conditions. Thus, this report aims to identify public interest in nephrological diseases and nephrologists during the pandemic.

\section{Methods}

Google Trends provides information on online search patterns of Google search engine. The search frequency is represented as relative search volume (RSV) indexed to all search quires. RSV values scaled from 0 to 100 ; wherein 100 corresponds to the highest interest for a particular search query (Google Trends 2020).

Search queries corresponding to a broad spectrum of nephrological diseases and related conditions were chosen. The total of 51 search queries were as follows: Minimal change disease, nephrotic syndrome, nephritic syndrome, focal segmental glomerulosclerosis, nephropathy, membranous nephropathy, glomerulonephritis, membranoproliferative glomerulonephritis, IgA nephropathy, thin basement membrane disease, Goodpasture disease, lupus nephritis, amyloidosis, hemolytic uremic syndrome, atypical hemolytic uremic syndrome, kidney biopsy, hematuria, proteinuria, diabetic nephropathy, chronic kidney disease, hypertension, renovascular hypertension, kidney cyst, autosomal dominant polycystic kidney disease, Alport syndrome, congenital kidney, nephrolithiasis, nephrocalcinosis, acute interstitial nephritis, chronic interstitial nephritis, vesicoureteral reflux, acute kidney injury, renal replacement therapy, hemodialysis, peritoneal dialysis, kidney transplantation, renal rejection, antibodymediated rejection, end-stage renal disease, urinary tract infection, cystitis, pyelonephritis, neurogenic bladder, renal mass, renal cell carcinoma, C3 glomerulopathy, obstructive nephropathy, Fabry disease, pulmonary-renal syndrome, renal osteodystrophy, and nephrologist.

On November 19, 2020, Google Trends was queried and its results were downloaded for each search keyword in the "United States," from January 1, 2016, to November 19, 2020 , selecting the "All categories." Two time intervals of 2020 (March 15-July 4 and July 5-October 31) were compared to similar time intervals of 2016 - 2019 for providing information on interest in different phases of the pandemic. To investigate changes in RSV between time intervals, we applied generalized estimation equations selecting the gamma model. All analyses were conducted in SPSS V.21.0 statistical package (IBM Corp.). A $p$-value $<0.05$ was considered to indicate statistical significance. Presentation of results are based on the recent review (Misra et al. 2021).

\section{Results}

In the March 15-July 4, 2020, time interval, the RSV for 38 among the 51 search terms (i.e., nephrotic syndrome, nephritic syndrome, focal segmental glomerulosclerosis, nephropathy, glomerulonephritis, membranoproliferative glomerulonephritis, IgA nephropathy, thin basement membrane disease, Goodpasture disease, hemolytic uremic syndrome, kidney biopsy, hematuria, diabetic nephropathy, chronic kidney disease, renovascular hypertension, kidney cyst, autosomal dominant polycystic kidney disease, Alport syndrome, congenital kidney, nephrolithiasis, nephrocalcinosis, acute interstitial nephritis, vesicoureteral reflux, hemodialysis, kidney transplantation, renal rejection, antibody-mediated rejection, urinary tract infection, cystitis, pyelonephritis, neurogenic bladder, renal mass, renal cell carcinoma, C3 glomerulopathy, obstructive nephropathy, pulmonary-renal syndrome, renal osteodystrophy, and nephrologist) were significantly lower; but 2 search queries (i.e., acute kidney injury, and amyloidosis) were significantly higher compared to previous 4 years (Table 1). 
Table 1 Relative search volume (RSV) of nephrological diseases and nephrologist

\begin{tabular}{|c|c|c|c|c|c|c|c|c|}
\hline & \multicolumn{4}{|c|}{ March 15-July 4} & \multicolumn{4}{|c|}{ July 5-October 31} \\
\hline & 2020 & 2016-2019 & $\%$ Change & $P$ value & 2020 & 2016-2019 & $\%$ Change & $P$ value \\
\hline Minimal Change Disease & $34.5 \pm 4.84$ & $37.97 \pm 2.12$ & -9.14 & 0.512 & $28.38 \pm 2.28$ & $35.81 \pm 1.81$ & -20.75 & 0.011 \\
\hline Nephrotic Syndrome & $62.75 \pm 1.87$ & $71.78 \pm 1.43$ & -12.58 & $<0.001$ & $68.53 \pm 1.9$ & $67.57 \pm 1.23$ & +1.42 & 0.674 \\
\hline Nephritic Syndrome & $33.56 \pm 2.69$ & $42.09 \pm 1.78$ & -20.27 & 0.008 & $40.24 \pm 3.28$ & $35.5 \pm 1.85$ & +13.35 & 0.209 \\
\hline Focal Segmental Glomerulosclerosis & $32.8 \pm 3.29$ & $41.32 \pm 1.83$ & -20.62 & 0.024 & $33.06 \pm 2.66$ & $38.75 \pm 1.64$ & -14.68 & 0.069 \\
\hline Nephropathy & $53.43 \pm 1.66$ & $64.68 \pm 1.40$ & -17.39 & $<0.001$ & $63.58 \pm 1.77$ & $64.35 \pm 1.42$ & -1.20 & 0.736 \\
\hline Membranous Nephropathy & $29.5 \pm 2.32$ & $35.09 \pm 1.72$ & -15.93 & 0.053 & $32.47 \pm 2.96$ & $35.1 \pm 1.4$ & -7.49 & 0.422 \\
\hline Glomerulonephritis & $52.44 \pm 2.72$ & $64.25 \pm 1.6$ & -18.38 & $<0.001$ & $50.71 \pm 2.24$ & $49.78 \pm 1.18$ & +1.87 & 0.715 \\
\hline Membranoproliferative Glomerulonephritis & $28.9 \pm 2.36$ & $41.56 \pm 2.25$ & -30.46 & $<0.001$ & $33.3 \pm 2.73$ & $40.12 \pm 2.12$ & -17.00 & 0.049 \\
\hline IgA Nephropathy & $49.19 \pm 3.13$ & $63.48 \pm 1.75$ & -22.51 & $<0.001$ & $51.88 \pm 2.58$ & $62.72 \pm 1.84$ & -17.28 & 0.001 \\
\hline Thin Basement Membrane Disease & $28.33 \pm 1.51$ & $41.02 \pm 2.2$ & -30.94 & $<0.001$ & $32.62 \pm 2.31$ & $37.52 \pm 1.45$ & -13.06 & 0.073 \\
\hline Goodpasture Disease & $36.07 \pm 3.17$ & $45.38 \pm 2.21$ & -20.52 & 0.016 & $45.13 \pm 4.45$ & $41.58 \pm 1.89$ & +8.54 & 0.463 \\
\hline Lupus Nephritis & $47.44 \pm 2.39$ & $46.56 \pm 1.48$ & +1.89 & 0.757 & $54.12 \pm 2.08$ & $50.56 \pm 1.73$ & +7.04 & 0.189 \\
\hline Amyloidosis & $36.81 \pm 2.46$ & $27.13 \pm 0.72$ & +35.68 & $<0.001$ & $46.18 \pm 1.2$ & $30.87 \pm 1.46$ & +49.60 & $<0.001$ \\
\hline Hemolytic Uremic Syndrome & $17.31 \pm 1.78$ & $24.91 \pm 1.51$ & -30.51 & 0.001 & $15.7 \pm 1.05$ & $20.56 \pm 0.86$ & -23.64 & $<0.001$ \\
\hline Atypical Hemolytic Uremic Syndrome & $27.33 \pm 3.61$ & $36.03 \pm 1.91$ & -24.15 & 0.033 & $27.08 \pm 1.00$ & $38.29 \pm 2.41$ & -29.28 & $<0.001$ \\
\hline Kidney Biopsy & $37.56 \pm 2.91$ & $51.08 \pm 1.77$ & -26.47 & $<0.001$ & $60.71 \pm 4.35$ & $50.12 \pm 1.75$ & +21.13 & 0.024 \\
\hline Hematuria & $59.25 \pm 1.44$ & $70.56 \pm 1.14$ & -16.03 & $<0.001$ & $74.41 \pm 1.66$ & $69.66 \pm 1.38$ & +6.82 & 0.028 \\
\hline Proteinuria & $64.69 \pm 2.72$ & $65.42 \pm 1.49$ & -1.12 & 0.813 & $70.41 \pm 3.43$ & $65.31 \pm 1.35$ & +7.81 & 0.167 \\
\hline Diabetic Nephropathy & $40.06 \pm 2.64$ & $48.27 \pm 1.63$ & -17.01 & 0.008 & $46.29 \pm 4.41$ & $48.4 \pm 1.81$ & -4.36 & 0.657 \\
\hline Chronic Kidney Disease & $60.81 \pm 1.42$ & $65.73 \pm 1.02$ & -7.49 & 0.005 & $73.82 \pm 2.84$ & $64.1 \pm 1.11$ & +15.16 & 0.001 \\
\hline Hypertension & $69.75 \pm 2.6$ & $64.41 \pm 0.99$ & +8.29 & 0.055 & $69.00 \pm 1.63$ & $63.44 \pm 1.06$ & +8.76 & 0.004 \\
\hline Renovascular Hypertension & $23.07 \pm 2.06$ & $34.83 \pm 2.35$ & -33.76 & $<0.001$ & $27.23 \pm 3.71$ & $28.04 \pm 1.35$ & -2.89 & 0.837 \\
\hline Kidney Cyst & $47.37 \pm 3.13$ & $66.06 \pm 1.31$ & -28.29 & $<0.001$ & $67.52 \pm 2.53$ & $67.66 \pm 1.37$ & -0.21 & 0.963 \\
\hline Autosomal Dominant Polycystic Kidney Disease & $23.35 \pm 2.51$ & $30.54 \pm 1.44$ & -23.54 & 0.013 & $32.12 \pm 3.24$ & $27.92 \pm 1.32$ & +15.04 & 0.23 \\
\hline Alport Syndrome & $27.37 \pm 2.2$ & $37.53 \pm 1.98$ & -27.07 & 0.001 & $33.0 \pm 2.32$ & $32.42 \pm 1.41$ & +1.79 & 0.833 \\
\hline Congenital Kidney & $36.75 \pm 3.09$ & $48.3 \pm 2.05$ & -23.91 & 0.002 & $39.12 \pm 3.32$ & $46.11 \pm 1.93$ & -15.16 & 0.069 \\
\hline Nephrolithiasis & $58.12 \pm 1.49$ & $63.48 \pm 1.75$ & -8.44 & 0.020 & $70.88 \pm 1.81$ & $65.41 \pm 1.42$ & +8.36 & 0.018 \\
\hline Nephrocalcinosis & $27.12 \pm 2.46$ & $38.32 \pm 1.57$ & -29.23 & $<0.001$ & $33.82 \pm 2.09$ & $35.67 \pm 1.45$ & -5.19 & 0.468 \\
\hline Acute Interstitial Nephritis & $11.25 \pm 0.97$ & $14.56 \pm 0.86$ & -22.73 & 0.011 & $11.88 \pm 1.12$ & $13.63 \pm 0.84$ & -12.84 & 0.214 \\
\hline Chronic Interstitial Nephritis & $35.12 \pm 4.18$ & $41.37 \pm 2.28$ & -15.11 & 0.190 & $36.40 \pm 3.83$ & $43.12 \pm 3.18$ & -15.58 & 0.177 \\
\hline Vesicoureteral Reflux & $36.56 \pm 3.15$ & $49.71 \pm 1.68$ & -26.45 & $<0.001$ & $41.88 \pm 3.2$ & $44.82 \pm 1.99$ & -6.56 & 0.436 \\
\hline Acute Kidney Injury & $58.87 \pm 1.75$ & $50.65 \pm 1.92$ & +16.23 & 0.002 & $70.23 \pm 2.91$ & $54.79 \pm 1.59$ & +28.18 & $<0.001$ \\
\hline Renal Replacement Therapy & $29.87 \pm 2.12$ & $34.47 \pm 1.45$ & -13.34 & 0.074 & $31.64 \pm 2.00$ & $32.52 \pm 1.83$ & -2.71 & 0.745 \\
\hline Hemodialysis & $68.06 \pm 1.92$ & $75.71 \pm 1.21$ & -10.10 & 0.001 & $72.47 \pm 2.54$ & $71.89 \pm 1.14$ & +0.81 & 0.837 \\
\hline Peritoneal Dialysis & $65.75 \pm 2.90$ & $68.65 \pm 1.32$ & -4.22 & 0.362 & $68.29 \pm 2.75$ & $66.75 \pm 1.53$ & +2.31 & 0.624 \\
\hline Kidney Transplantation & $21.33 \pm 2.25$ & $27.33 \pm 1.63$ & -21.95 & 0.031 & $21.62 \pm 2.29$ & $24.66 \pm 1.59$ & -12.33 & 0.276 \\
\hline Renal Rejection & $24.07 \pm 1.71$ & $33.54 \pm 2.16$ & -28.23 & 0.001 & $35.15 \pm 4.21$ & $33.67 \pm 1.57$ & +4.40 & 0.742 \\
\hline Antibody Mediated Rejection & $26.22 \pm 2.23$ & $43.4 \pm 3.18$ & -39.59 & $<0.001$ & $33.85 \pm 3.30$ & $40.16 \pm 2.60$ & -15.71 & 0.133 \\
\hline End Stage Renal Disease & $50.56 \pm 2.65$ & $55.42 \pm 1.65$ & -8.77 & 0.120 & $55.88 \pm 2.68$ & $60.67 \pm 1.94$ & -7.90 & 0.148 \\
\hline Urinary Tract Infection & $65.06 \pm 0.89$ & $78.60 \pm 0.66$ & -17.23 & $<0.001$ & $69.17 \pm 1.12$ & $80.25 \pm 0.66$ & -13.81 & $<0.001$ \\
\hline Cystitis & $61.75 \pm 1.48$ & $72.68 \pm 0.83$ & -15.04 & $<0.001$ & $70.88 \pm 0.94$ & $71.39 \pm 0.80$ & -0.71 & 0.677 \\
\hline Pyelonephritis & $62.62 \pm 1.80$ & $72.03 \pm 1.41$ & -13.06 & $<0.001$ & $76.17 \pm 1.52$ & $73.29 \pm 1.18$ & +3.93 & 0.136 \\
\hline Neurogenic Bladder & $53.00 \pm 2.17$ & $62.76 \pm 1.50$ & -15.55 & $<0.001$ & $65.35 \pm 2.48$ & $60.94 \pm 1.57$ & +7.24 & 0.134 \\
\hline Renal Mass & $45.62 \pm 3.06$ & $59.78 \pm 1.91$ & -23.69 & $<0.001$ & $59.35 \pm 3.33$ & $54.88 \pm 1.44$ & +8.15 & 0.219 \\
\hline Renal Cell Carcinoma & $48.12 \pm 1.44$ & $58.23 \pm 1.06$ & -17.36 & $<0.001$ & $57.23 \pm 1.90$ & $58.60 \pm 1.25$ & -2.34 & 0.549 \\
\hline C3 Glomerulopathy & $31.71 \pm 3.61$ & $40.66 \pm 2.62$ & -22.01 & 0.045 & $32.33 \pm 1.89$ & $43.77 \pm 3.99$ & -26.14 & 0.010 \\
\hline Obstructive Nephropathy & $25.00 \pm 0.40$ & $36.50 \pm 2.20$ & -31.51 & $<0.001$ & $27.33 \pm 0.49$ & $39.50 \pm 3.66$ & -30.81 & 0.001 \\
\hline
\end{tabular}


Table 1 (continued)

\begin{tabular}{|c|c|c|c|c|c|c|c|c|}
\hline & \multicolumn{4}{|c|}{ March 15-July 4} & \multicolumn{4}{|c|}{ July 5-October 31} \\
\hline & 2020 & 2016-2019 & $\%$ Change & $P$ value & 2020 & 2016-2019 & $\%$ Change & $P$ value \\
\hline Fabry Disease & $25.37 \pm 2.22$ & $28.67 \pm 1.69$ & -11.51 & 0.239 & $33.88 \pm 1.51$ & $26.83 \pm 1.40$ & +26.28 & 0.001 \\
\hline Pulmonary-Renal syndrome & $23.88 \pm 2.50$ & $29.23 \pm 1.46$ & -18.30 & 0.066 & $26.88 \pm 3.37$ & $27.08 \pm 1.67$ & -0.74 & 0.958 \\
\hline Renal Osteodystrophy & $25.80 \pm 2.71$ & $33.20 \pm 2.12$ & -22.29 & 0.032 & $23.52 \pm 3.12$ & $28.50 \pm 1.63$ & -17.47 & 0.159 \\
\hline Nephrologist & $60.12 \pm 2.64$ & $66.92 \pm 1.31$ & -10.16 & 0.021 & $75.52 \pm 1.83$ & $69.89 \pm 1.60$ & +8.06 & 0.021 \\
\hline
\end{tabular}

Data are means \pm standard error (generalized estimating equations)

In the July 5-October 31, 2020, time interval, the RSV for 8 among the 51 search queries (i.e., minimal change disease, membranoproliferative glomerulonephritis, IgA nephropathy, hemolytic uremic syndrome, atypical hemolytic uremic syndrome, urinary tract infection, c3 glomerulopathy, and obstructive nephropathy) were significantly lower; but 9 search queries (i.e., amyloidosis, kidney biopsy, hematuria, chronic kidney disease, hypertension, nephrolithiasis, acute kidney injury, Fabry disease, and nephrologist) were significantly higher compared to previous 4 years (Table 1, Fig. 1).

\section{Discussion}

Compared to the prior 4 years, analyses showed a significant decrease in RSV in the majority (75\%) of search queries over the time interval of March 15-July 4, 2020, while only 2 search queries showed a significant increase. However, this downward trend has reversed dramatically after this period. In the time interval of July 5-October 31, 2020, analyses showed a significant decrease in RSV in only 8 search queries, while an increase in 9 search terms was detected. The RSV of the majority of search queries (about 70\%) in this period was not

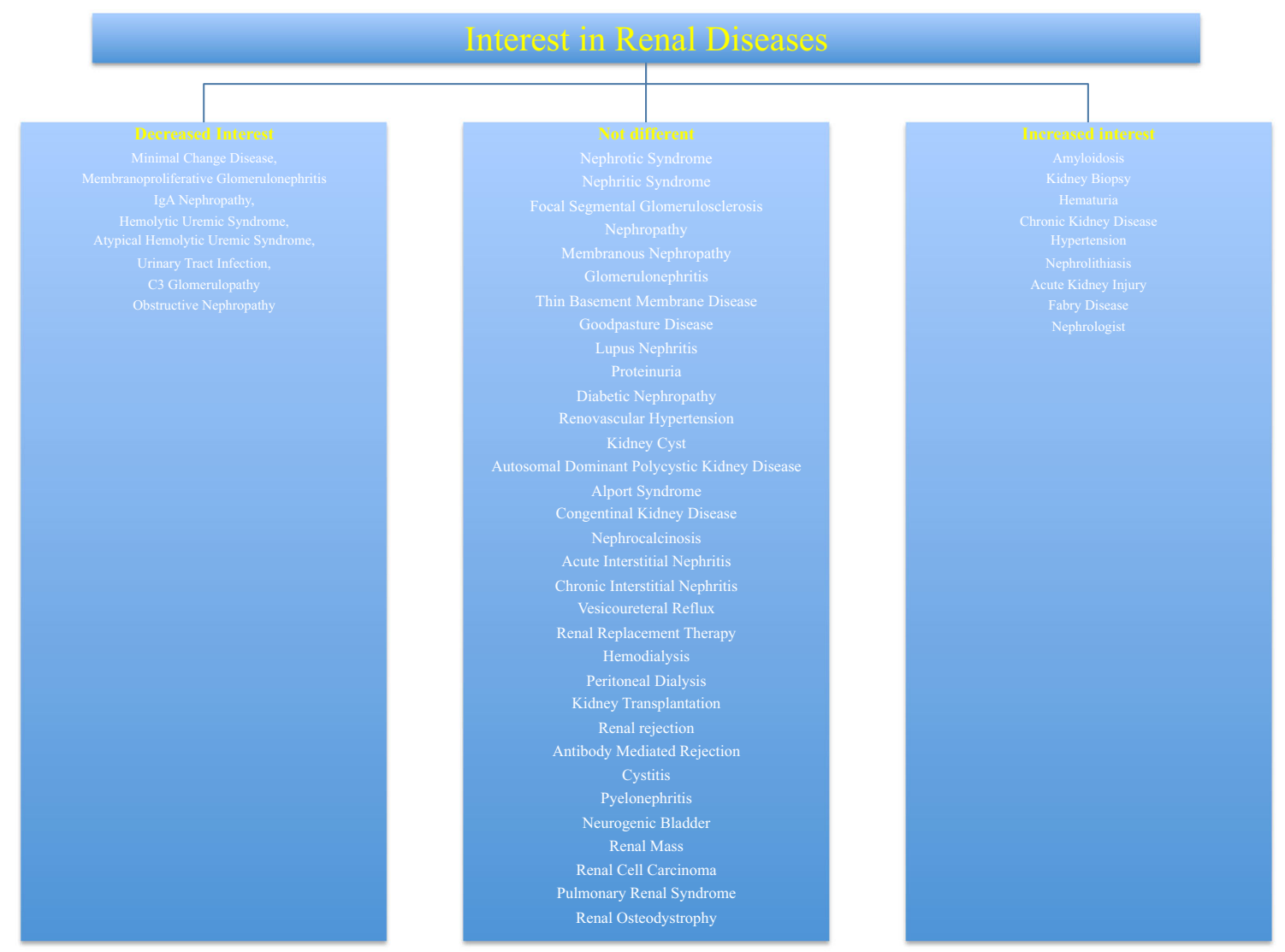

Fig. 1 The interest in nephrological diseases and nephrologist during the second phase of the pandemic (July 5-October 31, 2020) 
significantly different from similar time intervals of the previous 4 years. The RSV values for the search queries amyloidosis and acute kidney injury increased significantly in both periods compared to the previous 4 years.

Our findings revealed that public interest in nephrological conditions and procedures were reduced in the early pandemic. This is in line with the earlier studies evaluating the public's interest in other fields in the COVID-19 era (Bhambhvani et al. 2020; Kardeş et al. 2021c; Esen-Salman et al. 2021; Dhanda et al. 2020; Maccarone et al. 2021). The shift of patient attention from nephrological diseases and associated conditions to COVID-19 may be responsible for these observations in our and previous studies. The frequent decision to "shut-down" and "stay-at-home" orders by local authorities and the rapid spread of the disease after mid-March might be the reason for patients' attention being focused on COVID-19. However, the lack of a significant change in RSV values for many terms in the second period compared to the previous 4 years indicated that interest in nephrological diseases and associated conditions is improved after the early COVID-19 episode, and returned to its prior levels. The recovery of public interest in nephrological diseases may be associated not only with increased perceptions of COVID-19-related risk, but also lack of knowledge about potential risks, particularly among individuals with kidney disease or under immunosuppressive therapy. Furthermore, in this period, RSV of amyloidosis, kidney biopsy, hematuria, chronic kidney disease, hypertension, nephrolithiasis, acute kidney injury, and Fabry disease was found to have increased implying an increased need for information on these kidney diseases. In this period, intensive research on Fabry disease, which is a genetic disease and is not related to COVID-19, was also found surprising.

Interestingly, RSV values for the terms "amyloidosis" and "acute kidney injury" were increased compared to the previous 4 years in both time intervals. We cannot explain this increase for the term "amyloidosis." However, various studies have reported that the incidence of AKI in patients with COVID-19 is between 3 and $15 \%$ and this is associated with increased mortality (Zhou et al. 2020; Sİpahİ et al. 2020; Adapa et al. 2020; Öztürk et al. 2021). Also, AKI rates are $14.5-50 \%$ in patients with severe COVID-19 infection in the intensive care unit (Zhou et al. 2020; Sİpahİ et al. 2020; Adapa et al. 2020; Öztürk et al. 2021; Dirim et al. 2021). As this condition is known to be associated with COVID-19 since the early stage of the pandemic, the initial increase in RSV for search query "acute kidney injury" is not unexpected. Regardless, this finding implies the public informational needs for both amyloidosis and acute kidney injury.

Although not statistically significant $(p=0.055)$, there was an upward trend in RSV values for the search query "hypertension" in the early stage of the pandemic compared to previous years. This increase reached statistical significance in the second period. Published studies highlighted the significantly higher prevalence of hypertension among COVID-19 patients (Esler and Esler 2020; Öztürk et al. 2020; Fang et al. 2020). Hypertension was the most frequent coexisting condition in the largest of several case series published during the COVID-19 outbreak from China (Guan et al. 2020). This increased interest in hypertension can be partly explained by this factor.

It is interesting to note that there was decreased RSV for "nephrologist" between March 15-July 4, 2020, compared to the previous 4 years; however, increased interest was detected in the July 5-October 31, 2020, time interval. Although many government agencies and health systems are working every day to control the spread of infection, patients with underlying kidney diseases and kidney transplantation are vulnerable to the devastating effects of the COVID-19 pandemic (Pakhchanian et al. 2021). The mortality rate associated with COVID-19 is higher in dialysis and transplant recipients than in the general population (Ozturk et al. 2020; Demir et al. 2020; Sİpahİ et al. 2020; Jager et al. 2020; Petrilli et al. 2020; Dheİr et al. 2020; Oto et al. 2021). Regardless, the increased internet searches for nephrologists imply the increased need for nephrologists in the COVID-19 pandemic.

One of the important aspects of the study was that the search for chronic kidney diseases, like all chronic diseases also decreased during the early pandemic period. As shown in the second period of the study, it was seen that after the first shock event of the pandemic, public increasingly searched key terms related to chronic kidney disease (such as amyloidosis, kidney biopsy, hematuria, chronic kidney disease, hypertension, nephrolithiasis, acute kidney injury) were investigated further. This may be due to general population getting used to living with the pandemic. Alternatively, the demand for chronic renal disease can no longer be delayed.

There are limitations that should be taken into account when interpreting our results. First, Google Trends only offer data of searches made on the Google search engine. However, as it corresponds to $85 \%$ of all internet searches (Statcounter 2020), it probably mirrors all online searches. In addition, Google Trends does not offer access to the demographic data of its users. Therefore, subgroup analyzes cannot be made and our results can only be interpreted as the interest of the general public. Lastly, this study could not provide any specific data for reasons underlying the changing trends in the public interest. Despite these limitations, this study provides important information about how COVID-19 has impacted the interest in nephrology-related conditions. This information enables nephrologists to address the changed public interest and to design effective ways to manage patients with kidney disease during the pandemic.

In conclusion, between March 15 and July 4, 2020, there were significant decreases in search volumes for many nephrological diseases compared to the previous 4 years. However, this trend reversed between July 5 and October 
31,2020 . There was a marked increase in search volumes of amyloidosis, kidney biopsy, hematuria, chronic kidney disease, hypertension, nephrolithiasis, acute kidney injury, and Fabry disease. The increased need for information on these kidney diseases should be addressed. Furthermore, the search volume of the nephrologist showed an upward trend in the second period, indicating the need for nephrologists during the pandemic.

\section{Acknowledgements None}

Author contribution Ozgur Akin Oto planned the study, interpreted data, wrote the initial draft, and critically revised the manuscript. Sinan Kardeș planned the study, collected/analyzed/interpreted data, and critically revised the manuscript. Nurane Guller interpreted data and critically revised the manuscript. Seda Safak interpreted data and critically revised the manuscript. Ahmet Burak Dirim interpreted data and critically revised the manuscript. Yağmur Başhan interpreted data and critically revised the manuscript. Erol Demir interpreted data and critically revised the manuscript. Ayse Serra Artan interpreted data and critically revised the manuscript. Halil Yazıcı interpreted data and critically revised the manuscript. Aydin Turkmen planned the study, interpreted data, and critically revised the manuscript.

Data availability Data are available from the second author (SK) upon a reasonable request.

\section{Declarations}

Ethics approval and consent to participate Not applicable.

Consent for publication Not applicable.

Competing interests The authors declare no competing interests.

\section{References}

Adapa S, Chenna A, Balla M, Merugu GP, Koduri NM, Daggubati SR, Gayam V, Naramala S, Konala VM (2020) COVID-19 Pandemic Causing Acute Kidney Injury and Impact on Patients With Chronic Kidney Disease and Renal Transplantation. J Clin Med Res 12(6): 352-361. https://doi.org/10.14740/jocmr4200

Alola AA, Olowu FB (2020) The health scare of COVID-19 amidst pandemics and the immune-related pharmaceutical products spillovers in the USA. Environ Sci Pollut Res Int 27(36):45949-45956. https://doi.org/10.1007/s11356-020-11195-z

Arentz M, Yim E, Klaff L, Lokhandwala S, Riedo FX, Chong M, Lee M (2020) Characteristics and Outcomes of 21 Critically Ill Patients With COVID-19 in Washington State. JAMA. 323(16):16121614. https://doi.org/10.1001/jama.2020.4326

Bhambhvani HP, Tijerina JD, Parham MJ, Greenberg DR, Eisenberg ML (2020) Public Interest in Elective Urological Procedures in the COVID-19 Pandemic: A Google Trends Analysis. Urology Practice 7(6):496-501

Bomback AS, Canetta PA, Ahn W, Ahmad SB, Radhakrishnan J, Appel GB (2020) How COVID-19 Has Changed the Management of
Glomerular Diseases. Clinical journal of the American Society of Nephrology : CJASN 15(6):876-879. https://doi.org/10.2215/CJN. 04530420

Demir E, Uyar M, Parmaksiz E, Sinangil A, Yelken B, Dirim AB, Merhametsiz O, Yadigar S, Atan Ucar Z, Ucar AR, Demir ME, Mese M, Akin EB, Garayeva N, Safak S, Oto OA, Yazici H, Turkmen A (2020) COVID-19 in kidney transplant recipients: A multicenter experience in Istanbul. Transplant infectious disease : an official journal of the Transplantation Society 22(5):e13371. https://doi.org/10.1111/tid.13371

Deng Y, Liu W, Liu K, Fang YY, Shang J, Zhou L, Wang K, Leng F, Wei S, Chen L, Liu HG (2020) Clinical characteristics of fatal and recovered cases of coronavirus disease 2019 in Wuhan, China: a retrospective study. Chin Med J 133(11):1261-1267. https://doi.org/ 10.1097/CM9.0000000000000824

Dhanda AK, Leverant E, Leshchuk K, Paskhover B (2020) A Google Trends Analysis of Facial Plastic Surgery Interest During the COVID-19 Pandemic. Aesthet Plast Surg 44(4):1378-1380. https://doi.org/10.1007/s00266-020-01903-y

Dheİr H, Sİpahİ S, Yaylaci S, Çetİn ES, AB GÇ, Firat N et al (2020) Clinical course of COVID-19 disease in immunosuppressed renal transplant patients. Turkish journal of medical sciences 51:428-434. https://doi.org/10.3906/sag-2007-260

Dirim AB, Demir E, Yadigar S, Garayeva N, Parmaksiz E, Safak S, Bahat KA, Ucar AR, Oruc M, Oto OA, Medetalibeyoglu A, Basaran S, Orhun G, Yazici H, Turkmen A (2021) COVID-19 in chronic kidney disease: a retrospective, propensity score-matched cohort study. Int Urol Nephrol. https://doi.org/10.1007/s11255-021-02783-0

Doepker CP, Pakhchanian H, Raiker R, Lakhani DA, Hogg JP (2021) Google Trends Data of Radiologists Who Accept Medicare: A Potential Tool for Predicting State Demand. Curr Probl Diagn Radiol. https://doi.org/10.1067/j.cpradiol.2021.03.004

El-Sayed A, Aleya L, Kamel M (2021) COVID-19: a new emerging respiratory disease from the neurological perspective. Environ Sci Pollut Res Int. https://doi.org/10.1007/s11356-021-12969-9

Esen-Salman K, Akın-Çakıcı Ö, KardeȘ S, Salman A (2021) Public Interest in Dermatologic Symptoms, Conditions, Treatments, and Procedures during the COVID-19 Pandemic: Insights from Google Trends. Dermatol Ther 34:e14895. https://doi.org/10.1111/dth. 14895

Esler M, Esler D (2020) Can angiotensin receptor-blocking drugs perhaps be harmful in the COVID-19 pandemic? J Hypertens 38(5):781782. https://doi.org/10.1097/HJH.0000000000002450

Eysenbach G (2009) Infodemiology and infoveillance: framework for an emerging set of public health informatics methods to analyze search, communication and publication behavior on the Internet. J Med Internet Res 11(1):e11. https://doi.org/10.2196/jmir.1157

Fang L, Karakiulakis G, Roth M (2020) Are patients with hypertension and diabetes mellitus at increased risk for COVID-19 infection? Lancet Respir Med 8(4):e21. https://doi.org/10.1016/S22132600(20)30116-8

Google Trends. 2020. https://trends.google.com/trends/?geo=US. Accessed 1 Dec 2020

Guan WJ, Ni ZY, Hu Y, Liang WH, Ou CQ, He JX, Liu L, Shan H, Lei CL, Hui DSC, du B, Li LJ, Zeng G, Yuen KY, Chen RC, Tang CL, Wang T, Chen PY, Xiang J, Li SY, Wang JL, Liang ZJ, Peng YX, Wei L, Liu Y, Hu YH, Peng P, Wang JM, Liu JY, Chen Z, Li G, Zheng ZJ, Qiu SQ, Luo J, Ye CJ, Zhu SY, Zhong NS, China Medical Treatment Expert Group for Covid-19 (2020) Clinical Characteristics of Coronavirus Disease 2019 in China. N Engl J Med 382(18):1708-1720. https://doi.org/10.1056/NEJMoa2002032

Güdük M, Orhun Ö, Dursun AT, Küçüksüleymanoğlu D, Deniz Z, Usseli MI, Bozkurt B, Kardeș S, Ekși MȘ (2021) Impact of COVID-19 on 
interest in pediatric neurosurgery related symptoms, diseases, and treatments. J Neurosurg Sci. https://doi.org/10.23736/S0390-5616. 21.05416-3

Jager KJ, Kramer A, Chesnaye NC, Couchoud C, Sánchez-Álvarez JE, Garneata L, Collart F, Hemmelder MH, Ambühl P, Kerschbaum J, Legeai C, del Pino y Pino MD, Mircescu G, Mazzoleni L, Hoekstra T, Winzeler R, Mayer G, Stel VS, Wanner C, Zoccali C, Massy ZA (2020) Results from the ERA-EDTA Registry indicate a high mortality due to COVID-19 in dialysis patients and kidney transplant recipients across Europe. Kidney Int 98(6):1540-1548. https://doi. org/10.1016/j.kint.2020.09.006

Kardeș S (2021) Public interest in spa therapy during the COVID-19 pandemic: analysis of Google Trends data among Turkey. Int $\mathrm{J}$ Biometeorol 65:945-950. https://doi.org/10.1007/s00484-02102077-1

Kardeş E, Kardeş S (2021) Google searches for bruxism, teeth grinding, and teeth clenching during the COVID-19 pandemic. J Orofac Orthop. https://doi.org/10.1007/s00056-021-00315-0

Kardeș S, Kuzu AS, Pakhchanian H, Raiker R, Karagülle M (2021a) Population-level interest in anti-rheumatic drugs in the COVID-19 era: insights from Google Trends. Clin Rheumatol 40(5):20472055. https://doi.org/10.1007/s10067-020-05490-w

Kardes S, Kuzu AS, Raiker R, Pakhchanian H, Karagülle M (2021b) Public interest in rheumatic diseases and rheumatologist in the United States during the COVID-19 pandemic: evidence from Google Trends. Rheumatol Int 41(2):329-334. https://doi.org/10. 1007/s00296-020-04728-9

Kardeș S, Erdem A, Gürdal H (2021c) Public interest in musculoskeletal symptoms and disorders during the COVID-19 pandemic: Infodemiology study. Z Rheumatol. https://doi.org/10.1007/ s00393-021-00989-2

Kliger AS, Silberzweig J (2020) Mitigating Risk of COVID-19 in Dialysis Facilities. Clinical journal of the American Society of Nephrology : CJASN 15(5):707-709. https://doi.org/10.2215/CJN. 03340320

Kutlu Ö (2020) Analysis of dermatologic conditions in Turkey and Italy by using Google Trends analysis in the era of the COVID-19 pandemic. Dermatol Ther 33(6):e13949. https://doi.org/10.1111/dth. 13949

Lampos V, Miller AC, Crossan S, Stefansen C (2015) Advances in nowcasting influenza-like illness rates using search query logs. Sci Rep 5:12760. https://doi.org/10.1038/srep12760

Lentine KL, Vest LS, Schnitzler MA, Mannon RB, Kumar V, Doshi MD, Cooper M, Mandelbrot DA, Harhay MN, Josephson MA, Caliskan Y, Sharfuddin A, Kasiske BL, Axelrod DA (2020) Survey of US Living Kidney Donation and Transplantation Practices in the COVID-19 Era. Kidney international reports 5(11):1894-1905. https://doi.org/10.1016/j.ekir.2020.08.017

Loupy A, Aubert O, Reese PP, Bastien O, Bayer F, Jacquelinet C (2020) Organ procurement and transplantation during the COVID-19 pandemic. Lancet. 395(10237):e95-e96. https://doi.org/10.1016/ S0140-6736(20)31040-0

Lu FS, Hou S, Baltrusaitis K, Shah M, Leskovec J, Sosic R, Hawkins J, Brownstein J, Conidi G, Gunn J, Gray J, Zink A, Santillana M (2018) Accurate Influenza Monitoring and Forecasting Using Novel Internet Data Streams: A Case Study in the Boston Metropolis. JMIR Public Health Surveill 4(1):e4. https://doi.org/ 10.2196/publichealth. 8950

Maccarone MC, Kamioka H, Cheleschi S, Tenti S, Masiero S, Kardeș S (2021) Italian and Japanese public attention toward balneotherapy in the COVID-19 era. Environ Sci Pollut Res Int. https://doi.org/10. 1007/s11356-021-15058-Z
Mavragani A, Ochoa G (2019) Google Trends in Infodemiology and Infoveillance: Methodology Framework. JMIR Public Health Surveill 5(2):e13439. https://doi.org/10.2196/13439

Misra DP, Zimba O, Gasparyan AY (2021) Statistical data presentation: a primer for rheumatology researchers. Rheumatol Int 41(1):43-55. https://doi.org/10.1007/s00296-020-04740-z

Oto OA, Ozturk S, Turgutalp K, Arici M, Alpay N, Merhametsiz O, Sipahi S, Ogutmen MB, Yelken B, Altiparmak MR, Gorgulu N, Tatar E, Ozkan O, Ayar Y, Aydin Z, Dheir H, Ozkok A, Safak S, Demir ME, Odabas AR, Tokgoz B, Tonbul HZ, Sezer S, Ates K, Yildiz A (2021) Predicting the outcome of COVID-19 infection in kidney transplant recipients. BMC Nephrol 22:100. https://doi.org/ 10.1186/s12882-021-02299-w

Öztürk R, Taşova Y, Ayaz A (2020) COVID-19: pathogenesis, genetic polymorphism, clinical features and laboratory findings. Turkish journal of medical sciences 50(SI-1):638-657. https://doi.org/10. 3906/sag-2005-287

Ozturk S, Turgutalp K, Arici M, Odabas AR, Altiparmak MR, Aydin Z, Cebeci E, Basturk T, Soypacaci Z, Sahin G, Elif Ozler T, Kara E, Dheir H, Eren N, Suleymanlar G, Islam M, Ogutmen MB, Sengul E, Ayar Y, Dolarslan ME, Bakirdogen S, Safak S, Gungor O, Sahin I, Mentese IB, Merhametsiz O, Oguz EG, Genek DG, Alpay N, Aktas N, Duranay M, Alagoz S, Colak H, Adibelli Z, Pembegul I, Hur E, Azak A, Taymez DG, Tatar E, Kazancioglu R, Oruc A, Yuksel E, Onan E, Turkmen K, Hasbal NB, Gurel A, Yelken B, Sahutoglu T, Gok M, Seyahi N, Sevinc M, Ozkurt S, Sipahi S, Bek SG, Bora F, Demirelli B, Oto OA, Altunoren O, Tuglular SZ, Demir ME, Ayli MD, Huddam B, Tanrisev M, Bozaci I, Gursu M, Bakar B, Tokgoz B, Tonbul HZ, Yildiz A, Sezer S, Ates K (2020) Mortality analysis of COVID-19 infection in chronic kidney disease, haemodialysis and renal transplant patients compared with patients without kidney disease: a nationwide analysis from Turkey. Nephrology, dialysis, transplantation : official publication of the European Dialysis and Transplant Association - European Renal Association 35(12):20832095. https://doi.org/10.1093/ndt/gfaa271

ÖztÜrk S, Turgutalp K, Arici M, Çetİnkaya H, Altiparmak MR, Aydin Z et al (2021) Impact of Hospital-acquired Acute Kidney Injury on Covid-19 Outcomes in Patients with and without Chronic Kidney Disease: A multicentre, retrospective cohort study. Turk J Med Sci 51:947-961. https://doi.org/10.3906/sag-2011-169

Pakhchanian H, Raiker R, Mukherjee A, Khan A, Singh S, Chatterjee A (2021) Outcomes of COVID-19 in CKD Patients: A Multicenter Electronic Medical Record Cohort Study. Clin J Am Soc Nephrol 16:785-786. https://doi.org/10.2215/CJN.13820820

Petrilli CM, Jones SA, Yang J, Rajagopalan H, O'Donnell L, Chernyak Y et al (2020) Factors associated with hospital admission and critical illness among 5279 people with coronavirus disease 2019 in New York City: prospective cohort study. BMJ. 369:m1966. https://doi. org/10.1136/bmj.m1966

Pier MM, Pasick LJ, Benito DA, Alnouri G, Sataloff RT (2020) Otolaryngology-related Google Search trends during the COVID19 pandemic. Am J Otolaryngol 41(6):102615. https://doi.org/10. 1016/j.amjoto.2020.102615

Sİpahİ S, Dheİr H, ToÇoĞlu A, BektaȘ M, AÇikgÖz SB, GenÇ AC, Mutlu F, KÖroĞlu M, Erdem AF, Karabay O (2020) Characteristics and Mortality Determinants of COVID-19 Patients Undergoing Haemodialysis. Turkish journal of medical sciences 51:421-427. https://doi.org/10.3906/sag-2006-54

Statcounter. 2020. https://gs.statcounter.com/search-enginemarketshare/. Accessed 1 Dec 2020

Teng Y, Bi D, Xie G, Jin Y, Huang Y, Lin B, An X, Feng D, Tong Y (2017) Dynamic Forecasting of Zika Epidemics Using Google 
Trends. PLoS One 12(1):e0165085. https://doi.org/10.1371/journal. pone. 0165085

WHO (World Health Organization) (2021) https://covid19.who.int/. Accessed 10 Dec 2020

Yang X, Yu Y, Xu J, Shu H, Xia J, Liu H et al (2020) Clinical course and outcomes of critically ill patients with SARS-CoV-2 pneumonia in Wuhan, China: a single-centered, retrospective, observational study. Lancet Respir Med 8(5):475-481. https://doi.org/10.1016/S22132600(20)30079-5

Yin H, Sun T, Yao L, Jiao Y, Ma L, Lin L, Graff JC, Aleya L, Postlethwaite A, Gu W, Chen H (2021) Association between population density and infection rate suggests the importance of social distancing and travel restriction in reducing the COVID-19 pandemic. Environ Sci Pollut Res Int. https://doi.org/10.1007/s11356-02112364-4

Zhou F, Yu T, Du R, Fan G, Liu Y, Liu Z et al (2020) Clinical course and risk factors for mortality of adult inpatients with COVID-19 in Wuhan, China: a retrospective cohort study. Lancet. 395(10229): 1054-1062. https://doi.org/10.1016/S0140-6736(20)30566-3

Publisher's note Springer Nature remains neutral with regard to jurisdictional claims in published maps and institutional affiliations. 